\title{
Using Peer Feedback to Promote Clinical Excellence in Hospital Medicine
}

\author{
Molly A. Rosenthal, $M^{7} \odot$, Bradley A. Sharpe, $\mathrm{MD}^{2}$, and Lawrence A. Haber, $\mathrm{MD}^{7}$ \\ 'Division of Hospital Medicine, Priscilla Chan and Mark Zuckerberg San Francisco General Hospital and Trauma Center, Department of Medicine, \\ University of California, San Francisco, CA, USA; 'Division of Hospital Medicine, Department of Medicine, University of California, San Francisco, CA, \\ USA.
}

Hospitalists provide a significant amount of direct clinical care in both academic and community hospitals. Peer feedback is a potentially underutilized and low resource method for improving clinical performance, which lends itself well to the frequent patient care handoffs that occur in the practice of hospital medicine. We review current literature on peer feedback to provide an overview of this performance improvement tool, briefly describe its incorporation into multi-source clinical performance appraisals across disciplines, highlight how peer feedback is currently used in hospital medicine, and present practical steps for hospital medicine programs to implement peer feedback to foster clinical excellence among their clinicians.

KEY WORDS: peer feedback; professional development; clinical excellence; hospital medicine

J Gen Intern Med 35(12):3644-9

DOI: $10.1007 / \mathrm{s} 11606-020-06235-\mathrm{w}$

(c) Society of General Internal Medicine 2020

\section{CLINICAL CASE}

An early-career hospitalist is called to her annual meeting with the Chief of Service. She feels like her first year on faculty has been a steep learning curve but has yet to receive much reinforcing or corrective feedback regarding her clinical care, so she assumes she is performing as expected. The Chief congratulates her that her length of stay and readmission metrics are within the expected range for the hospitalist group but mentions having received feedback over the past few months from hospitalist colleagues that her handoffs are often not updated with the most accurate clinical information. When she asks for more details regarding these concerns, the Chief states that unfortunately that is all they know about the issue. Leaving the meeting, the hospitalist is embarrassed and unsure of how to improve her clinical aptitude. She yearns for more timely and structured feedback to proactively improve her clinical performance.

Received May 4, 2020

Accepted September 10, 2020

Published online September 21, 2020

\section{INTRODUCTION}

Hospital medicine is the nation's fastest growing specialty with more than 50,000 clinicians currently practicing in the USA. ${ }^{1}$ In both community and academic programs, hospitalists provide a significant amount of direct clinical care and clinical oversight. ${ }^{1}$ Many hospitalists begin practice immediately following residency training, where they subsequently develop and refine nascent practice patterns on the job. With an increasing presence in the acute care setting and demonstrated higher mortality rates for patients cared for by earlycareer hospitalists, ${ }^{2}$ tools that foster and improve clinical excellence are critically important.

Clinical excellence can be defined as the practices, attitudes, skills, and knowledge of an expert clinician that lead to delivering compassionate and informed patient care. ${ }^{3,4}$ Prioritizing the development of clinical excellence may result in better patient outcomes, clinician wellness, and faculty retention. ${ }^{5,6}$

Current means of promoting clinical development usually occurs at the individual level only during licensing, board recertification, and hospital credentialing via programs such as Continuing Medical Education, Maintenance of Certification, and Ongoing Professional Practice Evaluation, respectively. Across medical specialties, diverse methods to assess clinician performance have included standardized patients, video observation, portfolios or appraisals, and audits of medical records or written correspondence. ${ }^{7}$ These methods are resource-intensive, reliant on self-interpretation or delayed, indirect observations, often perceived as punitive, and result in uncertain impact on clinical practice. ${ }^{8}$ Within hospital medicine specifically, other described methods to promote clinical excellence include mentorship, case conferences, and clinician work groups. ${ }^{9}$ Such programs are dependent on more experienced clinician involvement, require dedicated non-clinical time, may be costly to implement, and do not provide timely, individualized feedback.

Peer feedback is a potentially underutilized method of clinical performance improvement, which overcomes many of the above-described barriers and lends itself well to the frequent patient care handoffs experienced in hospital medicine. We reviewed current literature on peer feedback to provide an overview of this performance improvement tool. We briefly describe its incorporation into multi-source clinical performance appraisals across disciplines, highlight how peer 
feedback is used currently in hospital medicine, and present practical steps for hospital medicine programs to implement peer feedback to foster clinical excellence among their clinicians.

\section{PEER FEEDBACK ACROSS MEDICINE}

Given with the intent to improve performance, peer feedback is insight from a colleague about the comparison between an observed performance and a standard. ${ }^{10}$ It has been used as a strategy to promote clinical excellence in medicine since the late 1950s. ${ }^{11,12}$ Peer feedback improves the accuracy of selfassessment when used as an external resource, avoiding the clinician's impulse to only seek out or incorporate affirmative feedback or apply unfairly negative perceptions. ${ }^{13-15}$

Peer feedback has been integrated into medical student and resident education, ${ }^{16,}{ }^{17}$ with feedback delivered via different modalities, including internet survey, facilitated video review, or during structured clinical examinations. ${ }^{18,}{ }^{19}$ In some programs, residents receive peer feedback to aid in professional development. In one sample from the Internal Medicine residency at the Mayo Clinic, 74 of the 103 participating residents found peer feedback to be a helpful supplement to standard faculty feedback. ${ }^{20}$ Separately, residency programs across seven institutions participated in the LOOP project, which evaluated the impact of providing resident clinicians with feedback on recent diagnostic decisions. ${ }^{21}$ As a result of participation in the feedback, resident clinicians reported an increased comfort with sharing feedback and increased selfefficacy in identifying and mitigating cognitive biases' negative effects. ${ }^{21}$ Certain multi-source feedback tools have been validated with student and resident physicians, including the mini-Clinical Evaluation Exercise (mini-CEX) ${ }^{22}$ and the Sheffield Peer Review Assessment Tool (SPRAT). ${ }^{23}$ Peer feedback is often an integral part of multi-source (or 360-degree) feedback, a process through which feedback is collected from a clinician's colleagues, supervisors, subordinates, and patients. ${ }^{24}$ While multi-source feedback is a valuable tool for performance improvement, ${ }^{25,} 26$ clinicians are most likely to incorporate feedback specifically from other clinicians with whom they have worked closely with and trust. ${ }^{27}$

In Canada and the United Kingdom (UK), peer feedback is also used in multi-source feedback during recertification processes. ${ }^{28,}{ }^{29}$ Canadian licensing authorities have utilized peer feedback for three decades as a part of a multi-source feedback program known as the Physician Achievement Review (PAR). ${ }^{30}$ The program provides an individualized "educational prescription" based off the assessments for clinicians who need or wish to enhance their skills. ${ }^{30}$ On initial review of the program, two-thirds of participating physicians indicated that they were considering or had implemented changes to their medical practice based on their PAR data. ${ }^{29}$ The UK General Medical Council requires multi-source feedback for the revalidation process. Qualitative analysis of the process by clinicians and reviewers found it to be a valuable source of feedback but expressed concern about the credibility in assessing poor performance. ${ }^{31}$

\section{PEER FEEDBACK IN HOSPITAL MEDICINE}

Although the exact number of participating programs is unknown, peer feedback is used in hospital medicine nationally to varying degrees. A 2019 multi-site survey of 198 pediatric hospitalists ${ }^{32}$ found that $60 \%$ of participants had participated in peer feedback that primarily focused on patient care and teaching skills, and $61 \%$ of those reported using a "standardized tool" for peer feedback activities. Commonly reported benefits of peer feedback included identifying areas for improvement, learning about other practitioners' approaches to working with trainees and patients, and creating mutually supportive relationships. ${ }^{32}$ Across sites, the greatest barrier to participation was clinicians' time, followed by discomfort receiving feedback from peers, non-specific or actionable feedback, and lack of validated peer feedback tools. ${ }^{32}$

For disciplines such as a hospital medicine, structured around shift-work and frequent handoffs, peer feedback can complete a clinical feedback loop. Clinical feedback loops relay data back to a clinician on clinical decisions and outcomes after care for a patient has been relinquished, when diagnoses may change. These loops help physicians minimize overconfidence ("no news is good news") and improve judgment to achieve maximal potential in a skill or competency. ${ }^{33}$ At Oregon Health and Science University, Bowen and colleagues evaluated the responses of 12 hospitalists and 10 internal medicine residents to clinical feedback from peers after learning that their provisional diagnosis was either consistent or inconsistent with the subsequent diagnosis. ${ }^{34}$ Reactions to confirmed diagnoses invoked positive emotional responses in all cases and reinforced practice patterns, while disconfirming feedback resulted in consistently negative emotional responses from participating hospitalists along with rationalizations mitigating the impact of a mistake. ${ }^{34}$ In qualitative interviews, both confirming and disconfirming cases resulted in anticipated changes in practice moving forward, ${ }^{34}$ highlighting the potential for peer feedback influence practice patterns in disciplines with discontinuous care patterns.

Within this same cohort of internal medicine clinicians, Bowen evaluated facilitators and barriers to feedback communication in the context of patient care transitions. ${ }^{35}$ Clinicians expressed reluctance to communicate diagnostic changes based on the anticipated receptivity of potentially negative feedback. Hospitalists' receptivity to clinical feedback was positively associated with the sender's time on a teaching service, clinical credibility, and status as a peer or junior colleague. ${ }^{35}$ Preference for a shared common workspace was also identified as important for feedback receptivity, as a shared space provides opportunity for spontaneous, informal feedback conversations. ${ }^{35}$ This study suggests the setting and 
format through which peer feedback may be best received are both important.

At Johns Hopkins, the hospital medicine program developed an internally validated scale to evaluate the clinical performance of 22 hospital medicine clinicians by comparing composite Press Ganey patient-satisfaction reports to a peer assessment survey. ${ }^{36}$ They found that high scores on the composite of the physician-specific Press Ganey questions correlated with peer assessment of humanism $(P=0.06){ }^{36}$ Despite Press Ganey's limitations of non-response bias, high ceiling rate, and low variation between questions attributed to clinicians,${ }^{37}$ their program was still able to identify clinicians on the ends of a spectrum: high performers for recognition and lower performers who might benefit from remediation. ${ }^{36} \mathrm{Nei}-$ ther the training nor the time required to complete and analyze the survey responses was not specified. Ideally, these findings would be replicated at another institution. Yet, this study demonstrates the feasibility of peer feedback to recognize variation in clinical excellence within a hospitalist program.

A more hands-on approach was used at Massachusetts General Hospital (MGH), with senior clinical advisors acting as clinical coaches to early-career hospitalists. ${ }^{38}$ Clinical coaching is a voluntary relationship between colleagues which focuses on a participant's strength and uses self-evaluation and feedback to improve clinical performance. ${ }^{39}$ The program at MGH entailed twelve volunteer senior clinical advisors with more than 5 years of post-residency experience to coach 25 early-career hospitalists on medical decision-making, data interpretation, and clinical exam findings. ${ }^{38}$ As a result of this program, most of the clinicians reported a change in their diagnostic approach $(80 \%)$, and at least one change in a patient's diagnosis over a 2 -week survey period $(56 \%){ }^{38}$ The program also resulted in $72 \%$ of the early-career hospitalists feeling more comfortable as an independent clinician, while $90 \%$ of the senior advisors expressed satisfaction with their role. ${ }^{38}$ While this program was well regarded, it was dependent on the availability of more experienced clinicians willing to serve in this capacity and did not include description of the training process for senior clinicians in the coach role.

The Division of Hospital Medicine at the University of California, San Francisco developed a related structured peer observation and feedback program to improve clinicians' teaching skills. ${ }^{40}$ Participants were trained in a 2 -h session to identify previously validated teaching behaviors using a structured observation tool and assigned to observe two teaching rounds over a year in a feedback dyad. Refresher courses for teaching skills were also offered to participants. In a pre- and post-survey analysis, participant confidence in giving feedback, receiving feedback, and self-reported teaching efficacy significantly increased. ${ }^{40}$ Structured peer observation programs demonstrate the potential of peer feedback on clinician skill building as well as comfort delivering and receiving feedback.

At a national level, the American Board of Internal Medicine (ABIM) developed the Teamwork Effectiveness
Assessment Module (TEAM) to use feedback to evaluate hospitalist interprofessional teamwork. ${ }^{41}$ The online module integrates qualitative and quantitative peer feedback as a part of a multi-source survey, self-assessment survey, and a peerled reflective component to generate individual development plans. ${ }^{41}$ Note that there was no mention of pre-training in the use of the tool or the amount of time spent completing the module. On TEAM pilot testing, all 15 participating hospitalists reported receiving meaningful, actionable information from the tool. ${ }^{41}$ Peer feedback can be used to assess and improve hospital clinicians' interprofessional practice, a core clinical competency in hospital medicine. ${ }^{42}$

\section{LIMITATIONS TO PEER FEEDBACK}

There are several limitations to peer feedback. First, the subjective nature of peer feedback may not accurately reflect true clinical performance and lead to bias in the reporting. Findings demonstrate that the higher the stakes of an evaluation, the more likely a peer is to report favorable findings. ${ }^{43}$ Thus, data generated from peer feedback programs for high-stakes clinical scenarios may skew positive. Second, there is no externally validated tool for providing peer assessment for hospitalists. ${ }^{44}$ Tools used for peer assessment in hospital medicine are often institution-specific, vary based on outcome of interest, and have not been externally validated. Depending on the method, peer feedback may be resource-intensive, especially if used as part of larger multi-source feedback program. Another important limitation to implementing a peer feedback program is cultural aversion to giving and receiving feedback. ${ }^{45}$ Outside of formal programs developed to give feedback on clinical teaching, ${ }^{40,46}$ hospitalists receive little training in delivering feedback on clinical competence to peers, limiting the development of comfort in this skillset. In a survey of pediatric hospitalists, $13 \%$ of respondents reported that their program's culture was not conducive to giving or receiving feedback and $35 \%$ felt uncomfortable participating in peer feedback with colleagues. ${ }^{32}$ To be effective, peer feedback requires the presence of a trusting relationship between colleagues and comfort providing such feedback.

\section{CONSIDERATIONS FOR USE IN HOSPITAL MEDICINE}

Peer feedback to promote clinical excellence exists along a spectrum of informal to formal sources of feedback (Fig. 1). Programs can follow accepted principles of providing feedback that is (1) based on direct observation; (2) well-timed and expected; (3) focused on specific observable behaviors relevant to the clinician's practice and institution; and (4) provided with an opportunity for the recipient to respond. ${ }^{12,}{ }^{14}$ Specific examples of recommended practices are included in Table 1.

The most informal method of peer feedback is to encourage communication, either informally or via structured means, at the time of patient handoffs or after transitions of care. This 


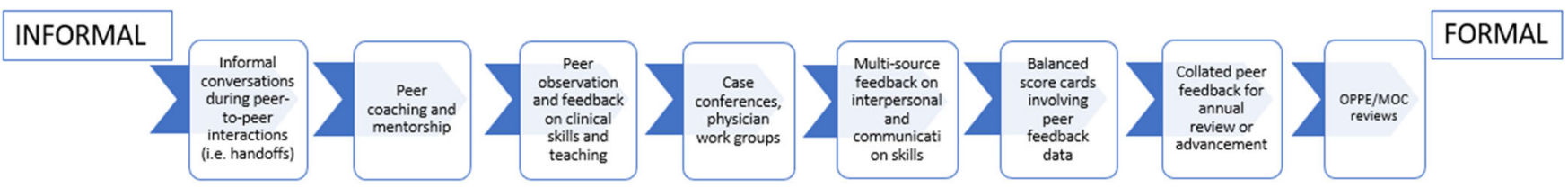

Fig. 1 Continuum of utilization of peer feedback in hospital medicine.

can form a clinical feedback loop, prompting the clinician to reflect on their management and clinical reasoning after further information is obtained or a diagnosis is reached. ${ }^{47}$ Providing peer feedback in these transition settings allows it to be expeditious, task-specific, and low inference due to feedback timeliness. $^{48}$

Conversations should begin with positive feedback to build a trusting relationship. ${ }^{49}$ Once the relationship is established, constructive feedback based on direct observations will be more likely to elicit change. ${ }^{50,51}$ The recipient should ask "why" to continue the conversation, even when it is praise. Examples of potential language to guide the recipient are provided in Table 2. Intentional reflection enhances peer feedback. ${ }^{52}$ Encouraging these conversations, as well as providing time and a space for this engagement, helps build an institutional culture where clinicians feel comfortable participating in feedback conversations and the expectation exists that such conversations will occur. ${ }^{53}$

A more formal method of implementing peer feedback is clinical coaching. ${ }^{38}$ The coaching relationship should be voluntary, non-evaluative, non-punitive, goal-directed, and involve feedback and self-reflection. ${ }^{54}$ Peer observation, often a part of peer coaching, has been shown to impact clinician

Table 1 Best Practices for Peer Feedback in Hospital Medicine

\begin{tabular}{|c|c|}
\hline & Examples \\
\hline $\begin{array}{l}\text { Based on principles of } \\
\text { effective feedback }\end{array}$ & $\begin{array}{l}\text { Based on direct observation } \\
\text { Well-timed and expected } \\
\text { Begin with positive feedback (ratio } \\
6: 1 \text { ideal) } \\
\text { Focused on specific, low-inference } \\
\text { observable behaviors } \\
\text { Provides an opportunity for the } \\
\text { recipient to respond }\end{array}$ \\
\hline $\begin{array}{l}\text { Integrated into the clinical } \\
\text { workflow }\end{array}$ & $\begin{array}{l}\text { Encourage feedback at the time of } \\
\text { handoffs and transitions of care } \\
\text { Encourage nocturnists to provide } \\
\text { positive and constructive feedback to } \\
\text { the daytime providers } \\
\text { Use EHR messaging for brief } \\
\text { follow-up information for admitting } \\
\text { providers }\end{array}$ \\
\hline $\begin{array}{l}\text { Provide time and space for } \\
\text { feedback conversations }\end{array}$ & $\begin{array}{l}\text { Communal team work room with the } \\
\text { space for one-on-one conversations } \\
\text { Optional follow-up form clinicians } \\
\text { can send to the new team clinician to } \\
\text { close the clinical feedback loop } \\
\text { Optional feedback form for new } \\
\text { clinician to send to former team } \\
\text { clinician to provide feedback }\end{array}$ \\
\hline $\begin{array}{l}\text { Encourage reflection and the } \\
\text { formation of an action plan }\end{array}$ & $\begin{array}{l}\text { During annual review meetings with } \\
\text { division leaders } \\
\text { Voluntary pairs can be given guides } \\
\text { for peer coaching conversations to } \\
\text { reflect on any sources of feedback } \\
\text { and develop action plans together }\end{array}$ \\
\hline
\end{tabular}

behavior in hospital medicine. ${ }^{40,55}$ Performance data extracted from an electronic health record (EHR) may be provided to facilitate discussions and support feedback with tangible objectivity. Peer coaching conversations should conclude with mutual reflection on the feedback and creation of an action plan for the clinician recipient to use for self-improvement. ${ }^{14,56}$ Examples of a range of specific and actionable goals may include increasing thromboembolic prophylaxis compliance, improving discharge summary timeliness, or diagnostic timeouts to mitigate heuristics that may have led to misdiagnosis. Formal coaching programs require an investment in training peer coaches and dedicated, non-clinical time for discussion.

Group-wide peer surveys, another example of a structured form of peer feedback, are competency assessments performed by clinicians with similar skills and responsibilities. Surveys may be anonymous, lessening clinician discomfort delivering feedback, though not necessarily mitigating discomfort receiving feedback. Recipients of peer surveys should be given a facilitated opportunity to respond and reflect on information received, which can be accomplished via peer coaching sessions, an annual departmental or division review process, or during academic advancement procedures. When developing group-wide surveys, the tool should consider questions addressing six domains of clinical competence: communication and interpersonal skills, humanism, professionalism, diagnostic acumen, commitment for patient care, and stewardship of the healthcare system and use of resources. ${ }^{36}$ Peer surveys used in residency training, such as SPRAT, may also be adapted for early-career clinicians. ${ }^{57}$ A minimum

Table 2 Statements to Facilitate an Effective Peer Feedback Conversation

\begin{tabular}{ll}
\hline \hline & Recommended statements \\
\hline $\begin{array}{l}\text { For clinician } \\
\text { providing feedback }\end{array}$ & $\begin{array}{l}\text { I really like the way you did } \\
\text { Can you tell me more about why you chose to } \\
\text { do } \text { ? }\end{array}$ \\
& $\begin{array}{l}\text { How did you feel about that patient outcome? } \\
\text { differently? }\end{array}$ \\
& $\begin{array}{l}\text { Based on prior experience, I might have done } \\
\text { instead. }\end{array}$ \\
& $\begin{array}{l}\text { I'm not sure I understand that plan. Can you } \\
\text { clarify for me what you mean? }\end{array}$ \\
For clinician receiving you tell me more about what you said \\
feedback & $\begin{array}{l}\text { Can yent well? } \\
\text { Is there anything you would have done } \\
\text { differently? } \\
\text { How have you seen other people manage this } \\
\text { more effectively? } \\
\text { Do you have any recommendations for me to } \\
\text { improve that? }\end{array}$ \\
\hline
\end{tabular}


of ten peer reviewers is necessary to achieve adequate reliability of survey responses. ${ }^{58}$ Thus, the volume of participants needed may limit this approach to larger hospital medicine programs.

Lastly, peer feedback can be incorporated into a clinician's balanced score card, or clinical dashboard, using data from a peer-to-peer survey. ${ }^{59,60}$ Balanced score cards were initially designed as a performance measurement tool for businesses to monitor company growth but have been used in hospital medicine to track group performance along domains reflective of practice values or pertinent outcomes. ${ }^{59}$ Such tools for clinical performance are resource-intensive to build and maintain and provide uncertain benefit at the individual clinician level. While more data is needed to assess their efficacy, peer feedback could easily be incorporated to any group's pre-existing tool.

\section{CONCLUSION}

Peer feedback is a potentially useful tool to promote clinical excellence in hospital medicine. Existing evidence supports that varied forms of peer feedback are feasible, improve clinician confidence in delivering and receiving feedback, and subjectively improve clinical decision-making and skill development. This narrative review presents the rationale for and a framework for hospital medicine programs to use peer feedback to foster clinical excellence. Areas of future research include examining the prevalence of and describing the nature of peer feedback programs in use, standardizing and validating tools to assess peer feedback in hospital medicine, and assessing the impact of peer feedback on objective measures of clinical performance and patient outcomes.

Corresponding Author: Molly A. Rosenthal, MD; Division of Hospital Medicine, Priscilla Chan and Mark Zuckerberg San Francisco General Hospital and Trauma Center, Department of Medicine, University of California, San Francisco, CA, USA (e-mail: Molly.Anderson@ucsf.edu).

\section{Compliance with Ethical Standards:}

Conflict of Interest: The authors declare that they do not have a conflict of interest.

\section{REFERENCES}

1. Wachter RM, Goldman L. Zero to 50,000 - the 20th anniversary of the hospitalist. N Engl J Med 2016;375(11):1009-11.

2. Goodwin JS, Salameh H, Zhou J, Singh S, Kuo Y-F, Nattinger AB. Association of hospitalist years of experience with mortality in the hospitalized Medicare population. JAMA Intern Med 2018;178(2): 196.

3. Kotwal S, Peña I, Howell $\mathbf{E}$, Wright $\mathbf{S}$. Defining clinical excellence in hospital medicine. J Contin Educ Heal Prof 2017;37(1):3-8.

4. Christmas C, Kravet SJ, Durso SC, Wright SM. Clinical excellence in academia: perspectives from masterful academic clinicians. Mayo Clin Proc 2008;83(9):989-94.

5. Durso SC, Christmas C, Kravet SJ, Parsons G, Wright SM. Implications of academic medicine's failure to recognize clinical excellence. Clin Med Res 2009;7(4):127-33.
6. Noah TL, Tolleson-Rinehart S, Meltzer-Brody S, Jordan JM, Kelly KJ, Eimers KM, et al. Application of assessment metrics for an academic department faculty development program. J Pediatr. 2018;195:5-8.el.

7. Overeem K, Faber MJ, Arah OA, Elwyn G, Lombarts KMJMH, Wollersheim HC, et al. Doctor performance assessment in daily practise: does it help doctors or not? A systematic review. Med Educ 2007;41(11):1039-49.

8. Davis DA, Thomson MA, Oxman AD, Haynes RB. Changing physician performance. A systematic review of the effect of continuing medical education strategies. JAMA. 1995;274(9):700-5.

9. Mansouri M, Lockyer J. A meta-analysis of continuing medical education effectiveness. J Contin Educ Heal Prof 2007;27(1):6-15.

10. Van De Ridder JMM, Stokking KM, McGaghie WC, Ten Cate OTJ. What is feedback in clinical education? Med Educ 2008;42(2):189-97.

11. Kubany AJ. Use of sociometric peer nominations in medical education research. J Appl Psychol 1957;41(6):389-94.

12. Ende J. Feedback in clinical medical education. JAMA. 1983;250(6):77781.

13. Davis DA, Mazmanian PE, Fordis M, Van Harrison R, Thorpe KE, Perrier L. Accuracy of physician self-assessment compared with observed measures of competence. JAMA. 2006;296(9):1094.

14. Kluger AN, DeNisi A. The effects of feedback interventions on performance: a historical review, a meta-analysis, and a preliminary feedback intervention theory. Psychol Bull 1996;119(2):254-84.

15. Sargeant J, MacLeod T, Sinclair $\mathbf{D}$, Power $\mathbf{M}$. How do physicians assess their family physician colleagues' performance? Creating a rubric to inform assessment and feedback. J Contin Educ Heal Prof 2011;31(2):87-94.

16. Weyrich P, Celebi N, Schrauth M, Möltner A, Lammerding-Köppel M, Nikendei C. Peer-assisted versus faculty staff-led skills laboratory training: a randomised controlled trial. Med Educ 2009;43(2):113-20.

17. Sheahan G, Reznick R, Klinger D, Flynn L, Zevin B. Comparison of faculty versus structured peer-feedback for acquisitions of basic and intermediate-level surgical skills. Am J Surg 2019;217(2):214-21.

18. Cushing A, Abbott S, Lothian D, Hall A, Westwood OMR. Peer feedback as an aid to learning - what do we want? Feedback. When do we want it? Now! Med Teach 2011;33(2):e105-12.

19. Ho K, Yao C, Novak Lauscher H, Koehler BE, Shojania K, Jamal S, et al. Remote assessment via video evaluation (RAVVE): a pilot study to trial video-enabled peer feedback on clinical performance. BMC Med Educ 2019;19(1):466.

20. Dupras DM, Edson RS. A survey of resident opinions on peer evaluation in a large internal medicine residency program. J Grad Med Educ 2011;3(2):138-43.

21. Lane KP, Chia C, Lessing JN, Limes J, Mathews B, Schaefer J, et al. Improving resident feedback on diagnostic reasoning after handovers: the LOOP project. J Hosp Med 2019;14(10):622-5.

22. Hatala R, Norman GR. In-training evaluation during an internal medicine clerkship. Acad Med 1999;74(10):s118-20.

23. Archer JC, Norcini J, Davies HA. Use of SPRAT for peer review of paediatricians in training. BMJ. 2005;330(7502):1251-3.

24. Al Ansari A, Donnon $\mathbf{T}$, Al Khalifa $\mathbf{K}$, Darwish A, Violato C. The construct and criterion validity of the multi-source feedback process to assess physician performance: a meta-analysis. Adv Med Educ Pract 2014;5:39.

25. Violato C, Lockyer $\mathbf{J}$. Self and peer assessment of pediatricians, psychiatrists and medicine specialists: implications for self-directed learning. Adv Health Sci Educ 2006; 11(3):235-44.

26. Miller A, Archer J. Impact of workplace based assessment on doctors' education and performance: a systematic review. BMJ. 2010;341:710.

27. van Schaik SM, O'Sullivan PS, Eva KW, Irby DM, Regehr G. Does source matter? Nurses' and physicians' perceptions of interprofessional feedback. Med Educ 2016;50(2):181-8.

28. Elwyn G, Lewis M, Evans R, Hutchings $\mathbf{H}$. Using a "peer assessment questionnaire" in primary medical care. Br J Gen Pract 2005;55(518):690-5.

29. Hall W, Violate C, Lewkonia R, Lockyer J, Fidler H, Toews J, et al. Assessment of physician performance in Alberta: the physician achievement review. CMAJ. 1999;161(1):52-7.

30. Page GG, Bates J, Dyer SM, Vincent DR, Bordage G, Jacques A, et al. Physician-assessment and physician-enhancement programs in Canada. CMAJ. 1995;153(12):1723-8.

31. Hill JJ, Asprey A, Richards SH, Campbell JL. Multisource feedback questionnaires in appraisal and for revalidation: a qualitative study in UK general practice. Br J Gen Pract 2012;62(598):e314. 
32. McDaniel CE, Singh AT, Beck JB, Birnie K, Fromme HB, Ginwalla CF et al. Current practices and perspectives on peer observation and feedback: a national survey. Acad Pediatr 2019;19(6):691-7.

33. Dhaliwal G. Clinical excellence: make it a habit. Acad Med 2012;87(11): 1473 .

34. Bowen JL, Ilgen JS, Regehr G, ten Cate O, Irby DM, O'Brien BC. Reflections from the rear view mirror: internal medicine physicians' reactions to clinical feedback after transitions of responsibility. Acad Med 2019;94:1953-60.

35. Bowen JL, Boscardin CK, Chiovaro J, ten Cate O, Regehr G, Irby DM et al. A view from the sender side of feedback: anticipated receptivity to clinical feedback when changing prior physicians' clinical decisions-a mixed methods study. Adv Health Sci Educ 2020;25(2):263-282.

36. Bhogal HK, Howell E, Torok H, Knight AM, Howell E, Wright S, et al. Peer assessment of professional performance by hospitalist physicians. South Med J 2012;105(5):254-8.

37. North F, Tulledge-Scheitel SM. Patient satisfaction with providers: do patient surveys give enough information to help providers improve specific behaviors. Heal Serv Res Manag Epidemiol 2019;6:1-6.

38. Iyasere CA, Baggett M, Romano J, Jena A, Mills G, Hunt DP. Beyond continuing medical education. Acad Med 2016;91(12):1647-50.

39. Sekerka LE, Chao J. Peer coaching as a technique to foster professional development in clinical ambulatory settings. J Contin Educ Heal Prof 2003;23(1):30-7

40. Mookherjee S, Monash B, Wentworth KL, Sharpe BA. Faculty development for hospitalists: structured peer observation of teaching. J Hosp Med 2014;9(4):244-50.

41. Chesluk BJ, Reddy S, Hess B, Bernabeo E, Lynn L, Holmboe E. Assessing interprofessional teamwork: pilot test of a new assessment module for practicing physicians. J Contin Educ Heal Prof 2015;35(1):3-10.

42. Nichani S, Crocker J, Fitterman N, Lukela M. Updating the core competencies in hospital medicine-2017 revision: introduction and methodology. An Off Publ Soc Hosp Med J Hosp Med 2017;12(4):283.

43. Norcini JJ. Peer assessment of competence. Med Educ 2003;37(6):539-43.

44. Evans R, Elwyn G, Edwards A. Review of instruments for peer assessment of physicians. BMJ. 2004;328(7450):1240.

45. Mann K, van der Vleuten C, Eva K, Armson H, Chesluk B, Dornan T, et al. Tensions in informed self-assessment: how the desire for feedback and reticence to collect and use it can conflict. Acad Med 2011;86(9):1120-7.

46. Skeff KM. Improving clinical teaching. Evaluation of a national dissemination program. Arch Intern Med 1992;152(6):1156-61.

47. Regehr G, Mylopoulos M. Maintaining competence in the field: learning about practice, through practice, in practice. J Contin Educ Heal Prof 2008;28:19-23
48. Sargeant J, Lockyer J, Mann K, Holmboe E, Silver I, Armson H, et al. Facilitated reflective performance feedback. Acad Med 2015;90(12):1698706.

49. The Ideal Praise-to-Criticism Ratio [Internet]. [cited 2019 Oct 29]. Available from: https://hbr.org/2013/03/the-ideal-praise-to-criticism.

50. Eva KW, Regehr G. Effective feedback for maintenance of competence: from data delivery to trusting dialogues. CMAJ. 2013;185(6):463-4.

51. Sargeant J, Mann K, Ferrier S. Exploring family physicians' reactions to multisource feedback: perceptions of credibility and usefulness. Med Educ 2005;39(5):497-504.

52. Sargeant J, Bruce D, Campbell CM. Practicing physicians' needs for assessment and feedback as part of professional development. J Contin Educ Heal Prof. 2013;33 Suppl 1 (Suppl. 1):S54-62.

53. Ramani S, Könings KD, Mann K V, Pisarski EE, van der Vleuten CPM About politeness, face, and feedback: exploring resident and faculty perceptions of how institutional feedback culture influences feedback practices. Acad Med 2018;93(9):1348-58.

54. Schwellnus H, Carnahan H. Peer-coaching with health care professionals: what is the current status of the literature and what are the key components necessary in peer-coaching? A scoping review. Med Teach 2014;36(1):38-46.

55. Artenstein AW, Higgins TL, Seiler A, Meyer D, Knee AB, Boynton G, et al. Promoting high value inpatient care via a coaching model of structured, interdisciplinary team rounds. Br J Hosp Med 2015;76(1):415 .

56. Ivers $\mathbf{N}$, Jamtvedt $\mathbf{G}$, Flottorp $\mathbf{S}$, Young $\mathbf{J M}$, Odgaard-Jensen $\mathbf{J}$, French SD, et al. Audit and feedback: effects on professional practice and healthcare outcomes. Cochrane Database Syst Rev 2012;(6).

57. Sasaki H, Archer J, Yonemoto N, Mori R, Nishida T, Kusuda S, et al. Assessing doctors' competencies using multisource feedback: validating a Japanese version of the Sheffield Peer Review Assessment Tool (SPRAT). BMJ Open 2015;5(6):e007135.

58. Ramsey PG, Carline JD, Blank LL, Wenrich MD. Feasibility of hospitalbased use of peer ratings to evaluate the performances of practicing physicians. Acad Med 1996;71(4):364-70.

59. Hwa M, Sharpe BA, Wachter RM. Development and implementation of a balanced scorecard in an academic hospitalist group. J Hosp Med 2013;8(3):148-53.

60. Leep Hunderfund AN, Park YS, Hafferty FW, Nowicki KM, Altchuler SI, Reed DA. A multifaceted organizational physician assessment program. Mayo Clin Proc Innov Qual Outcomes 2017;1(2):130-40.

Publisher's Note Springer Nature remains neutral with regard to jurisdictional claims in published maps and institutional affiliations. 